\title{
An efficient design strategy for a whole-cell biosensor based on engineered ribosome binding sequences
}

\author{
Qing Yu • Yan Li • Anzhou Ma $\cdot$ Weifeng Liu • \\ Hailin Wang $\cdot$ Guoqiang Zhuang
}

Received: 3 July 2011 /Revised: 16 August 2011 /Accepted: 6 September 2011 /Published online: 25 September 2011

(C) Springer-Verlag 2011

\begin{abstract}
In prokaryotes, the ribosome binding sequence (RBS), located in the $5^{\prime}$ untranslated region ( $5^{\prime}$ UTR) of an mRNA, plays a critical role in enhancing mRNA translation and stability. To evaluate the effect of the RBS on the sensitivity and signal intensity of an environmental whole-cell biosensor, three Escherichia coli-based biosensors that respond to benzene, toluene, ethylbenzene, and the xylenes (BTEX) were constructed; the three biosensors have the same $P u$ promoter and $x y l R$ regulator from the Pseudomonas putida TOL plasmid but differ in the engineered RBS in their reporter genes. The results from time and dose-dependent induction of luminescence activity by 2-chlorotoluene showed that the BTEX-SE and BTEX-SD biosensors with engineered RBS had signal intensities approximately 10-35 times higher than the primary BTEX-W biosensor. The limits of detection (LOD) of the BTEX-SE and BTEX-SD biosensors were also significantly lower than the LOD of the BTEX-W biosensor $\left(20 \pm 5 \mu \mathrm{mol} \mathrm{L} \mathrm{L}^{-1}\right.$ and $25 \pm$ $5 \mu \mathrm{mol} \mathrm{L}{ }^{-1}$ vs. $120 \pm 10 \mu \mathrm{mol} \mathrm{L}{ }^{-1}$ ). Moreover, the BTEXSE and BTEX-SD biosensors responded three times more rapidly to the analytes. These results suggest that rationally designed RBS in the 5' UTR of a reporter gene may be a promising strategy for increasing the sensitivity, signal intensity, and response speed of whole-cell biosensors.
\end{abstract}

Q. Yu $\cdot$ Y. Li $\cdot$ A. Ma $\cdot$ H. Wang $\cdot$ G. Zhuang $(\triangle)$

Research Center for Eco-Environmental Sciences,

Chinese Academy of Sciences,

P.O. Box 2871, Beijing 100085, China

e-mail: gqzhuang@rcees.ac.cn

W. Liu

State Key Laboratory of Microbial Technology,

Shandong University,

Jinan 250100 Shandong, China
Keywords Whole-cell biosensor - Ribosome binding sequence $\cdot$ Signal intensity $\cdot$ Detection sensitivity

\section{Introduction}

Our environment is being polluted with an increasing number of industrial and domestic pollutants, resulting in the contamination of water, atmosphere, and soil. Therefore, it is essential to develop rapid and efficient methods to evaluate the environmental risks of pollutants, especially for their biotoxicity and bioavailability. Because of their low cost, ability to detect bioavailability, and ease-of-use, whole-cell biosensors have been developed and used widely as simple and practical approaches to the detection of a variety of agents, including heavy metals, toxic cellular organics, and metabolic products $[1,2]$. Moreover, biosensors can be customized with dimensions small enough to monitor the dispersal of analytes in the microenvironment [3, 4]. However, despite these advantages, and with the exception of heavy metals, wholecell biosensors can efficiently detect most analytes only at micromolar concentrations. Moreover, low signal intensities hinder detection when fluorescent proteins and single-copy reporter systems are used for in-situ assessment of bioavailability $[5,6]$. Therefore, efforts should be taken to overcome these limitations for the practical application of whole-cell biosensors.

Traditionally, the strategy for construction of a wholecell biosensor is based on a specific network of transcriptional regulation. In this network, a particular ligand binds a transcription factor, which in turn alters its affinity toward specific DNA sequences, resulting in differential access of RNA polymerase to the promoter and differential expression of mRNA [7, 8]. On the basis of this process, many successful efforts in the past few decades, for example 
engineered promoters, directed evolution of regulatory proteins, and reporter options, have improved the sensitivity and signal intensity of whole-cell biosensors [9-11].

In prokaryotes, the $5^{\prime}$ untranslated region (5' UTR) of an mRNA has a significant effect on translational efficiency and mRNA stability by directing the initiation codon to the $\mathrm{P}$ site of the small ribosomal subunit and by masking endonuclease recognition sites in mRNAs [12-14]. It is clear that two major motifs in the $5^{\prime}$ UTRs of bacterial mRNAs, the Shine-Dalgarno (SD) sequence and translational enhancers, are directly involved in initiation of translation [15-18]. The SD sequence affects translational efficiency through its base-pairing with the anti-SD sequence of the 16S ribosomal RNA [19, 20]. In addition, a translational enhancer, usually an $\mathrm{A} / \mathrm{U}$-rich motif located further upstream in the $5^{\prime}$ UTR, can also improve mRNA translational efficiency by interacting with the $\mathrm{S} 1$ protein of the ribosome [21]. A recent study showed that among 162 completed prokaryotic genomes the number of the SDdirected genes varied from $11.6 \%$ to $90.8 \%$, which implies that the populations of non-SD-directed genes (i.e., those not containing a SD-like sequence in their $5^{\prime}$ UTRs) are significant, although the translation initiation mechanism for these mRNAs is unclear [14]. However, there are no reports about whether an RBS can improve the sensitivity and the signal intensity of a whole-cell biosensor or improve a strategy based on the translational level of a whole-cell biosensor.

In this study, based on typical RBS signatures, three types of whole-cell biosensor with the same transcriptional regulation unit but different engineered RBS were designed and tested. The results clearly demonstrate that the RBS has a significant effect on the sensitivity and signal intensity of a whole-cell biosensor. The results also suggest that the rational design of a reporter gene $5^{\prime}$ UTR may be a promising strategy for increasing the sensitivity and signal intensity of whole-cell biosensors.

\section{Materials and methods}

Construction of the biosensor plasmids

Plasmid DNA was isolated using the BAC/PAC DNA isolation system (Omega Bio-Tec, USA). When necessary, DNA fragments were purified from agarose gels using the Omega Bio-Tec (USA) gel extraction kit. General DNA purification was performed with the Omega Bio-Tec Cycle Pure kit. All restriction endonucleases, the high-fidelity thermophilic DNA polymerase (Vent DNA polymerase) and T4 ligase were obtained from NEB (USA). DNA oligonucleotide primers were synthesized by Invitrogen (Beijing Office, China). Nucleotide sequences were determined using an Applied Biosystems Model 377 Prism DNA sequencer (Augct, Beijing, China).

The $P u$ promoter was amplified from the TOL plasmid of Pseudomonas putida ATCC 33015 (ATCC, USA) using the polymerase chain reaction (PCR) and primers $\mathrm{P}_{1}\left(5^{\prime}\right.$ ATTA $\left.G C G G C C G C C C C G G G A A A G C G C G A T G A A C-3^{\prime}\right)$ and $\mathrm{P}_{2}$ (5'-ACTGGGATCCTCACAGACTCCAGGCGTAACG-3') containing NotI and BamHI restriction enzyme digestion sites (shown in bold italics). Purified PCR products and the pGEM-luc plasmid were digested with NotI and $B a m \mathrm{HI}$ and ligated to create the plasmid pGP. The $x y l R$ gene was amplified with primers $\mathrm{P}_{3}$, (5'-CGATCTCGAGATTTTAATGTGGGCTGCTTGGT-3') and $\mathrm{P}_{4}$, (5'-GTACGAGCTCTTTTCACACAACCTGGGGCG-3') and inserted into the $\mathrm{XhoI}$ and $\mathrm{SacI}$ sites of pGP to create the plasmid pGPX (Table 1).

Because the pGEM-luc vector is a lacZ inserted plasmid, to eliminate the lacZ promoter and the lacZ gene in pGEM-luc vector, primers $\mathrm{P}_{5}$ (5'-AATTGCGGCCGCGTCGACCTGCAGGCATGCTCTAGAGGAAATTGTAAGCGTTAATAT$\left.3^{\prime}\right)$ and $\mathrm{P}_{6}\left(5^{\prime}\right.$-GACTGAGCTCTCTTCCGCTTCCTCGCTC$3^{\prime}$ ) containing NotI and SacI digestion sites were used to amplify the fragment containing ori, $\mathrm{Amp}^{\mathrm{r}}$, and $\mathrm{fl}$ ori from the pGEM-luc plasmid. After NotI and SacI digestion, this fragment was ligated to the cassette from the pGPX plasmid to form the pBTEX plasmid.

To prevent possible ribosome skipping [20], the luc gene of pBTEX was amplified using primers $\mathrm{P}_{7}\left(5^{\prime}\right.$ GGGCCCGGATCCAAATGGAAGA-3') containing a Bam HI site and primers $\mathrm{P}_{8}\left(5^{\prime}\right.$-CGATCTCGAGCTATCATTACAATTTGGACTTTCCGCCC-3') containing three termination codons (underlined) and an $\mathrm{XhoI}$ site and replaced by this PCR fragment to construct pBTEX-W $[1,20]$.

To construct plasmids with a modified RBS, the luc gene of pBTEX was replaced by a $l u c$ fragment amplified with primers $\mathrm{P}_{9}$ (5'ACTGGGATCCAAGGAGATATACATATG-

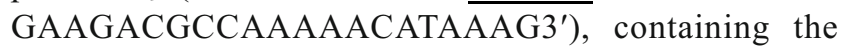
RBS sequence (underlined) from the T7 phage $g 10$ gene [22], and $\mathrm{P}_{8}$ to obtain plasmid pBTEX-SD. The luc gene of pBTEX was replaced by the same method with $\mathrm{P}_{10}\left(5^{\prime}\right.$ ACTGGGATCCTTAACTTTAAGAAGGAGATATACATATGGAAGAC $\overline{\text { GCCAAAAACATAAAG3'), }}$ containing the same SD sequence plus an enhancer (underlined) located near the $5^{\prime}$ end and $\mathrm{P}_{8}$ to obtain plasmid pBTEX-SE. DNA sequencing and restriction digest analyses of the fragments verified the proper sequences. The three plasmids pBTEX-W, pBTEX-SD, and pBTEX-SE were transformed into Escherichia coli $\mathrm{DH} 5 \alpha$ (Tiangen Biotech, China) to create the corresponding whole-cell biosensors. 
Table 1 Strains and plasmids used in this study

\begin{tabular}{|c|c|c|}
\hline Strains or plasmids & Relevant characteristics & Reference/origin \\
\hline Escherichia coli $\mathrm{DH} 5 \alpha$ & $\begin{array}{l}\mathrm{F}^{-} \varphi 80 \mathrm{lacZ} \Delta \mathrm{M} 15 \Delta(\mathrm{lacZYA}-\operatorname{argF}) \mathrm{U} 169 \text { deoR recA1 } \\
\text { endA1 hsdR17 }\left(\mathrm{r}_{\mathrm{k}}^{-}, \mathrm{mk}^{+}\right) \text {phoA supE44 } \lambda^{-} \\
\text {thi-1 gyrA96 relA1. }\end{array}$ & Tiangen Biotech (Peking, China) \\
\hline Pseudomonas putida ATCC33015 & Tol*, BETX* & ATCC \\
\hline pGEM-luc & luc gene, $\mathrm{Amp}^{\mathrm{r}}$, pUC replicon, luc::lacZ & Promega \\
\hline pGP & $l u c, P u$ from Tol, $A m p^{\mathrm{r}} \mathrm{pUC}$ replicon, luc::lacZ & This study \\
\hline pGPX & $l u c, x y l R$ and $P u$ from Tol, $A m p^{\mathrm{r}}$, pUC replicon, luc::lacZ & This study \\
\hline pBTEX & $l u c, x y l R$ and $P u$ from Tol, $A m p^{\mathrm{r}}$, $\mathrm{pUC}$ replicon & This study \\
\hline pBTEX-W & $l u c, x y l R$ and $P u$ from Tol, $A m p^{\mathrm{r}}$, $\mathrm{pUC}$ replicon & This study \\
\hline pBTEX-SD & $l u c$ with $\mathrm{SD}, x y l R$ and $P u$ from Tol, $\mathrm{Amp}^{\mathrm{r}}$, $\mathrm{pUC}$ replicon & This study \\
\hline pBTEX-SE & $l u c$ with SD and enhancer, $x y l R$ and $P u$ from Tol, $A m p^{\mathrm{r}}, \mathrm{pUC}$ replicon & This study \\
\hline
\end{tabular}

All strains and plasmids used in this study are shown in this table

Tol* and BETX* denote the TOL plasmid and the ability to grow on culture medium with benzene, toluene, ethylbenzene, and the xylenes as carbon source. $A m p^{r}$ denotes resistance to ampicillin

Induction of luciferase by 2-chlorotoluene

Single colonies of $E$. coli $\mathrm{DH} 5 \alpha$ cells harboring the corresponding biosensor plasmids were grown in $50 \mathrm{~mL}$ Luria-Bertani (LB) medium containing $100 \mu \mathrm{mol} \mathrm{\textrm {L } ^ { - 1 }}$ ampicillin at $37{ }^{\circ} \mathrm{C}$. Cells were left to grow in log phase (8 to $12 \mathrm{~h}$ ) to an optical density at $600 \mathrm{~nm}$ (OD600) of 1.2. After this growth period, the cell culture was diluted with LB medium to an OD600 of 0.4, and luciferase expression was induced by mixing $5 \mathrm{~mL}$ diluted culture with $5 \mathrm{~mL} \mathrm{LB}$ medium containing increasing amounts of 2-chlorotoluene dissolved in DMSO as described by Ikeno et al. [23]. Induction was performed in 100-mL glass vials followed by incubation at $23{ }^{\circ} \mathrm{C}$ and $250 \mathrm{rpm}$ for $30 \mathrm{~min}$, and the culture was cooled on ice for $10 \mathrm{~min}$ before luciferase activity was detected. Luciferase activity was measured using the E1500 luciferase assay system and Glomax-Muti microplate multimode reader (Promega, USA) in accordance with the supplier's instructions.

\section{RNA preparation}

RNA was extracted from cells grown in the presence or absence of $250 \mu \mathrm{mol} \mathrm{L} \mathrm{L}^{-1}$ 2-chlorotoluene using the $\mathrm{SV}$ Total RNA isolation system (Promega). RNA samples were eluted with DEPC-treated water (Takara, Japan), and OD 260/280 measurements were obtained by use of a Nano Drop 2000 spectrophotometer (Thermo, USA). Samples with OD 260/280 ratios between 1.8 and 2.1 and concentrations $\sim 300 \mathrm{ng} \mu \mathrm{L}^{-1}$ were used for subsequent analyses.
cDNA synthesis

For quantitative PCR analysis of RNA, cDNA synthesis was performed using the M-MLV reverse transcriptase (RT; Promega). Briefly, $1 \mu \mathrm{g}$ RNA template was mixed with random hexamer primers in less than $15 \mu \mathrm{L}$ water, heated to $70{ }^{\circ} \mathrm{C}$ and then immediately cooled on ice. Next, $5 \mu \mathrm{L}$ M-MLV $5 \times$ reaction buffer, $1.25 \mu \mathrm{L}$ dNTP mixture (10 mmol L ${ }^{-1}$ each), 25 units recombinant RNasin ribonuclease inhibitor (Promega), and 200 units M-MLV RT were added with nuclease-free water (Takara) to a final volume of $25 \mu \mathrm{L}$. The reaction was incubated for $60 \mathrm{~min}$ at $37^{\circ} \mathrm{C}$.

Quantitative real-time polymerase chain reaction (qRT-PCR)

A housekeeping gene, rpoS, was used as an internal standard to calculate the relative quantity of each luc reporter gene mRNA [24]. The levels of rpoS mRNA with induction and the luc mRNA with and without induction were calculated relative to that of rpoS without induction.

The qRT-PCR reactions were performed in triplicate using the MX3005P real-time PCR system (Stratagene, USA) and GoTaq qPCR Master Mix (Promega). Primers $\left(\mathrm{P}_{11}\right.$, 5' GAGATACGCCCTGGTTCCTG3' and $\mathrm{P}_{12}, 5^{\prime}$ TGCATACGACGATTCTGTGATT3' for luc. $\mathrm{P}_{13}, 5^{\prime}$ TAACTTGCGTCTGGTGGTAAAA3' and $\mathrm{P}_{14}, 5^{\prime}$ CGTATGTTGAGAAGCGGAAACC3' for rpoS) were obtained from Invitrogen (USA). The qRT-PCR reactions were performed in a $25-\mu \mathrm{L}$ reaction with $0.2 \mathrm{mmol} \mathrm{L}^{-1}$ primer. The reaction mixture was denatured at $95^{\circ} \mathrm{C}$ for 2 min and subjected to 40 
cycles of the following thermal conditions: $95^{\circ} \mathrm{C}(15 \mathrm{~s}), 57^{\circ} \mathrm{C}$ $(30 \mathrm{~s})$, and $72{ }^{\circ} \mathrm{C}(30 \mathrm{~s})$. All values reported are means from three independent experiments.

Methods used in data analysis

To evaluate detection sensitivity, the signal-to-noise ratio (SNR) was defined as the signal value of an effector-exposed sample divided by the signal value of its no-effector control. The limit of detection (LOD) was calculated as described elsewhere [25].

Data from three separate experiments were normalized. Origin version 7.5 was used to generate nonlinear least-squares fits of the data to the Hill equation:

$y=y_{\max }-\left\{\left(y_{\max }-y_{\min }\right) /\left(1+K_{1 / 2} \times[2-\text { chlorotoluene }]^{1 / n}\right.\right.$

as described by Willardsonin and colleagues [1]. In this equation, $y$ is the luminescence at a given concentration of 2-chlorotoluene, $y_{\max }$ is the maximum luminescence at the saturating concentration of 2-chlorotoluene, and $y_{\min }$ is the luminescence at a 2-chlorotoluene concentration of zero. $K_{1 / 2}$ is the concentration of 2-chlorotoluene at which the half-maximum effect is observed, and $n$ is the Hill coefficient, $n_{\text {app }}$.

The relative amounts of rpoS mRNA and the luc gene mRNAs were quantitated by qRT-PCR using the method reported by Schmittgen [26].

\section{Results and discussion}

Construction of plasmids with different RBS

in whole-cell biosensors

We constructed three plasmids, pBTEX-W, pBTEX-SD, and pBTEX-SE, each designed to express a firefly luciferase gene in response to benzene, toluene, ethylbenzene, and the xylenes (BTEX). Each plasmid contained the same BTEX-response elements from the Pseudomonas putida TOL plasmid, but they differed in the RBS for the luc reporter gene (Fig. 1). As shown in Fig. 1a, the primary plasmid pBTEX-W, which lacked a canonical SD sequence in the $5^{\prime}$ UTR, was constructed as described elsewhere [1]. The $P u$ promoter was inserted just upstream of the $l u c$ gene between the BamHI and NotI restriction sites. The promoter fragment spans $333 \mathrm{bp}$ of the TOL plasmid $P u$ region, including the upstream regulatory sequences for XylR binding, the ntr/nif-24 and 12 promoter sequences, and the transcription initiation site. The $x y l R$ regulatory unit was placed directly downstream of the luc gene in the same orientation as luc between the $\mathrm{XhoI}$ and $\mathrm{SacI}$ sites. The SD sequence (AGGAG) from the T7 phage g10 gene was introduced into the RBS site of the luc gene in pBTEX-W to create pBTEX-SD (Fig. 1b). A nine-base enhancer sequence, TTAACTTTA, was introduced upstream of the RBS in BTEX-SD to create the plasmid BTEX-SE (Fig. 1c). When E. coli DH5 $\alpha$ cells were transformed with these plasmids, consistent luminescence signals in response to 2-chlorotoluene could be detected.

Dose-dependent induction of luminescence activity with 2-chlorotoluene

The dose-dependent response of the biosensors to 2chlorotoluene at $30 \mathrm{~min}$ had a sigmoidal dependence on 2-chlorotoluene concentration, and the data fit the Hill equation well (Fig. 2). A nonlinear least-squares fit of the data also gave different $K_{1 / 2}$ values, which represent the concentrations of 2-chlorotoluene required for halfmaximum signal intensity. The BTEX-W biosensor had a $K_{1 / 2}$ of $114.6 \pm 7.6 \mu \mathrm{mol} \mathrm{L}{ }^{-1}$ (mean \pm standard deviation), higher than the $K_{1 / 2}$ of BTEX-SE and BTEX-SD, which were $88.1 \pm 5.1 \mu \mathrm{mol} \mathrm{L}^{-1}$ and $48 \pm 3.3 \mu \mathrm{mol} \mathrm{L}^{-1}$, respectively. The signal intensity of the BTEX-W biosensor increased slowly during the course of detection. Specifically,

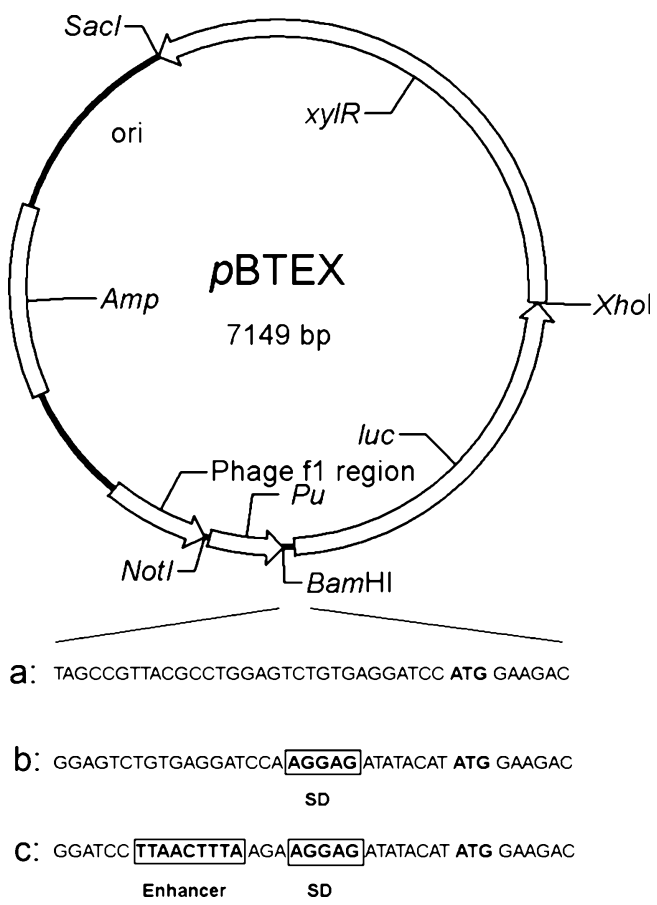

Fig. 1 Plasmid map and schematic diagram of the reporter plasmids. Important features of the BTEX series of biosensors are indicated, including the location and orientation of the $P u$ promoter, the $l u c$ gene, and the $x y l R$ transcriptional activator gene. $a, b$, and $c$ show the $5^{\prime}$ UTR sequences of the luc gene of biosensors BTEX-W, BTEX-SD, and BTEX-SE, respectively. The SD sequence of the biosensors and the A/U-rich enhancer of the BTEX-SE biosensor are shown by rectangular frames and denoted in bold face. The translational initiation codon ATG is also in bold face 


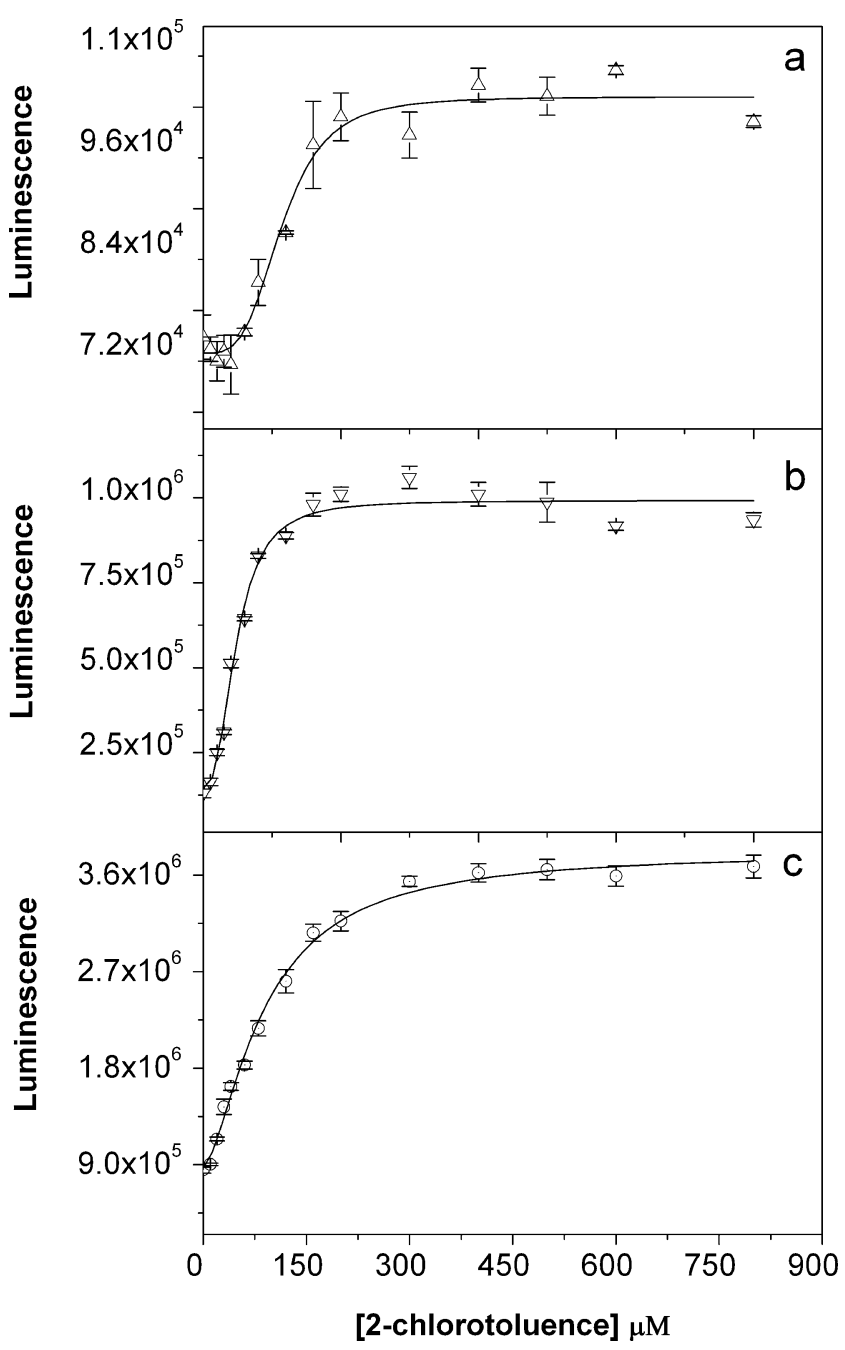

Fig. 2 The 2-chlorotoluene concentration dependence of biosensor cell luminescence. Shown are measurements of the luminescence from biosensors BTEX-W (a), BTEX-SD (b), and BTEX-SE (c) induced by different concentrations of 2-chlorotoluene. The error bars represent the standard deviations of three replicates of each sample within the same experiment. Curves represent the nonlinear least-squares fit of the data to the Hill equation

there was no apparent increase at concentrations below $60 \mu \mathrm{mol} \mathrm{L}{ }^{-1}$ (Fig. 2a). In contrast, the signal intensities of the other two biosensors, especially BTEX-SD, increased rapidly before the maximum signal intensity was reached (Fig. 2b, c). In addition, the slopes of the Hill equation for the three biosensors correlated well with the SNR results. Interestingly, the BTEX-SE biosensor achieved the highest signal intensity, but the BTEX-SD biosensor had the highest SNR and the highest slope among the three biosensors. To understand this phenomenon, the mRNA expression and mRNA stability for each biosensor should be investigated further. Nevertheless, there are differences between the BTEX-SD and BTEX-SE biosensors in performance; the
LOD values of both biosensors with an SD sequence or an SD sequence plus enhancer sequence were lower than that of BTEX-W (25 $\pm 5 \mu \mathrm{mol} \mathrm{L}{ }^{-1}, 20 \pm 5 \mu \mathrm{mol} \mathrm{L}{ }^{-1}$ vs. $120 \pm$ $10 \mu \mathrm{mol} \mathrm{L}{ }^{-1}$ at $30 \mathrm{~min}$, Fig. 2). These results and the aforementioned observations indicate that the RBS contained in the 5' UTR of a reporter gene has significant effects on the sensitivity and signal intensity of the whole-cell biosensors.

Time-dependent induction of luciferase activity with 2-chlorotoluene

Figure 3 shows the time courses of signal intensities in $E$. coli DH5 $\alpha$ cells harboring the three different plasmids with or without induction by $250 \mu \mathrm{mol} \mathrm{L}{ }^{-1} 2$-chlorotoluene. On induction, the signal intensities expressed by BTEX-SD and BTEX-SE reached $1.93 \times 10^{6} \mathrm{U}$ and $6.43 \times 10^{6} \mathrm{U}$, respectively, at 120 min (means of three replicates); these values were approximately 10 and 35 times higher than the signal from the primary biosensor BTEX-W. These results are consistent with the known ability of SD sequences and A/AU-rich translational enhancers to increase translational efficiency up to 100 times by serving as high-affinity binding sites for the ribosome $[15,16,27]$. In the absence of 2-chlorotoluene, the signal intensities also increased over the same period as a result of cell growth, but the pattern was obviously different among the three whole-cell biosensors. Compared with the extremely weak SNR of BTEX-W, which was $0.98 \pm 0.02$ at $5 \mathrm{~min}$ and $1.5 \pm 0.02$ at $120 \mathrm{~min}$ (Fig. 3c), the SNR of BTEX-SD and BTEX-SE rapidly reached $3.17 \pm 0.08$ and $1.62 \pm 0.05$ at $5 \mathrm{~min}$, and further increased to $10.25 \pm 0.27$ and $4.45 \pm 0.05$ at $120 \mathrm{~min}$. Therefore, unlike the primary biosensor BTEX-W, which only marginally distinguished the SNR after $15 \mathrm{~min}$, the BTEX-SD and BTEX-SE biosensors achieved much higher SNR values within $5 \mathrm{~min}$. Even at lower concentrations of effector (50 $\mu \mathrm{mol} \mathrm{L}{ }^{-1}$ 2-chlorotoluene), both the BTEX-SD and BTEX-SE biosensors performed well within $5 \mathrm{~min}$; in contrast, the BTEX-W biosensor was completely unable to detect the analytes within 5 min (data not shown). These results indicated that the signals from the biosensors with either an SD sequence or an SD sequence plus a translational enhancer can readily distinguish the induced signal from the un-induced control by achieving high signal intensity and reduced detection time, properties which are quite useful for in-situ assessments of bioavailability.

mRNA quantitation

To calculate the relative amount of mRNA from each luc reporter gene, we used a housekeeping gene, rpoS, as an internal standard. The amount of rpoS mRNA in the biosensor-containing cells subjected to induction was almost the same as the amount of rpoS mRNA in cells 


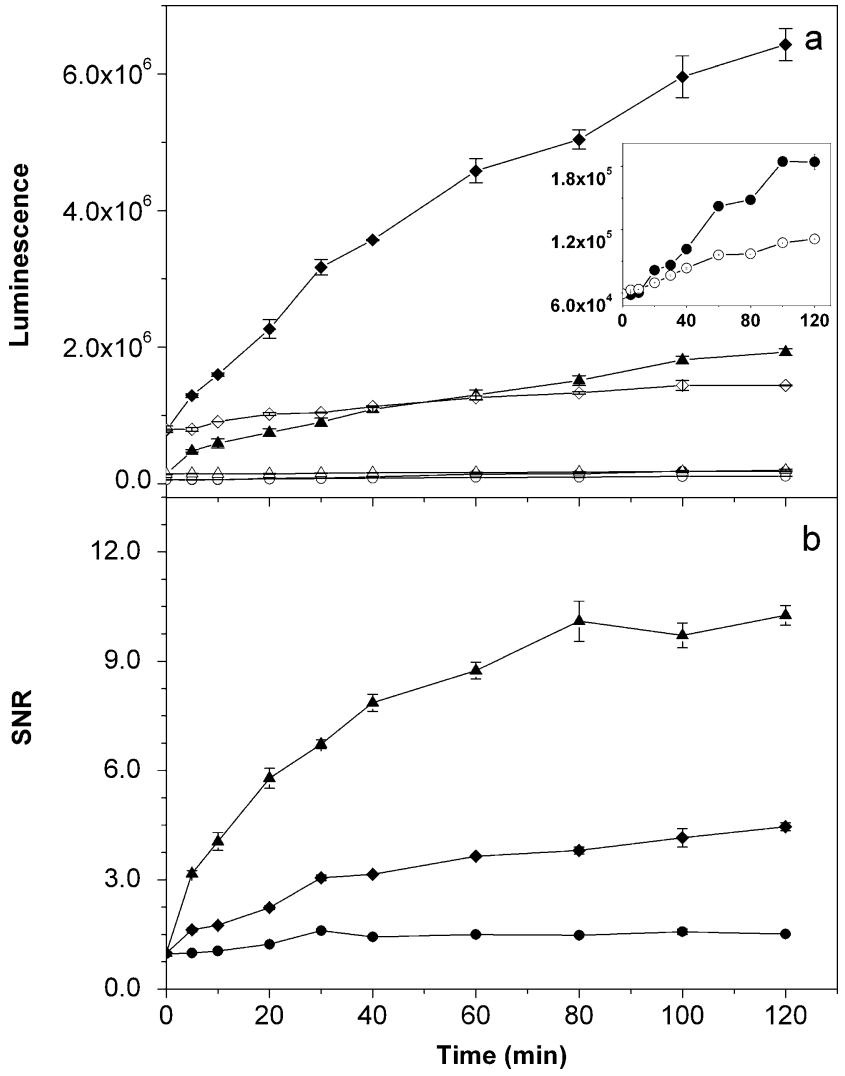

Fig. 3 Comparison of the luminescence and SNR of the three whole-cell biosensors during the course of 2-chlorotoluene induction. Shown are the time-dependent luciferase expression measurements and SNR values from BTEX-W (filled circles, empty circles), BTEX-SD (filled triangles, empty triangles) and BTEX-SE (filled diamonds, empty diamonds) plasmids. The solid symbols represent induced samples and their SNR whereas the open symbols represent the un-induced samples. Panel a shows the induced and un-induced luminescence activity of the BTEX-W, BTEX-SD and BTEX-SE biosensors. The inset in panel a shows the signal intensity of the BTEX-W biosensor, which was considerably weaker than for the BTEX-SD and BTEX-SE biosensors. Panel $\mathbf{b}$ shows the SNR of the three biosensors

without induction (Fig. 4). This result confirms that transcription of rpoS is unaffected by growth conditions and is suitable for use as an internal standard.

The relative amount of $l u c$ mRNA induced from the BTEX-SD biosensor was $29.1 \pm 5.1$, which was about three times as much as the $l u c$ mRNA derived from BTEX-W and BTEX-SE, which were $9.8 \pm 2.1$ and $12.3 \pm 1.7$, respectively (Fig. 4). There were no significant differences between the relative amounts of luc mRNA without induction; the amounts were $6.8 \pm 1.0$ for BTEX-W, $8.7 \pm 1.2$ for BTEXSD, and $7.7 \pm 1.7$ for BTEX-SE (Fig. 4).

The relative amount of induced BTEX-SD luc mRNA was three times higher than the mRNA from BTEX-W. However, this finding does not mean that the transcriptional efficiency was improved by insertion of the SD sequence, because no transcriptional motifs were modified. The result is likely to be because the BTEX-SD luc mRNA is more stable as a result of the SD insertion. In E. coli, mRNA degradation is a complex process that includes an initial, rate-limiting endonucleolytic cleavage (usually mediated by RNase E) followed by $3^{\prime}-5^{\prime}$ exonucleolytic degradation of the cleavage products [28-30]. Endonucleolytic attacks can be blocked to some extent by increased translational efficiency because, at higher rates of translation, ribosomes occlude a greater number of endonuclease recognition sites $[12,13]$. Therefore, it is likely that the SD-mediated increased translational efficiency of the BTEX-SD luc mRNA led to increased stability of the mRNA.

Although the BTEX-SD and BTEX-SE biosensors shared the same SD sequence, they did not express the same amounts of luc mRNA. This difference may be because the AU-rich translational enhancer in BTEX-SE promoted rapid decay of its mRNA. When located within $5^{\prime}$ UTRs, the A/AU rich motifs can serve as translational enhancers by interacting with ribosomal protein $\mathrm{S} 1$, an essential component of the $E$. coli translational machinery [13, 30, 31]. However, AU-rich single stranded regions have also been shown to be targets for RNase E, thereby bringing about rapid mRNA decay [32-35]. Thus, RNase E susceptibility induced by the A/U-rich motif may explain why the BTEX-SE and BTEX-SD biosensors produced different amounts of mRNA despite sharing the same SD sequence.

Our results show that the BTEX-SE biosensor has the highest signal intensity and lowest amount of luc mRNA; thus, the BTEX-SE reporter mRNA has the highest translational efficiency. Although a high translational effi-

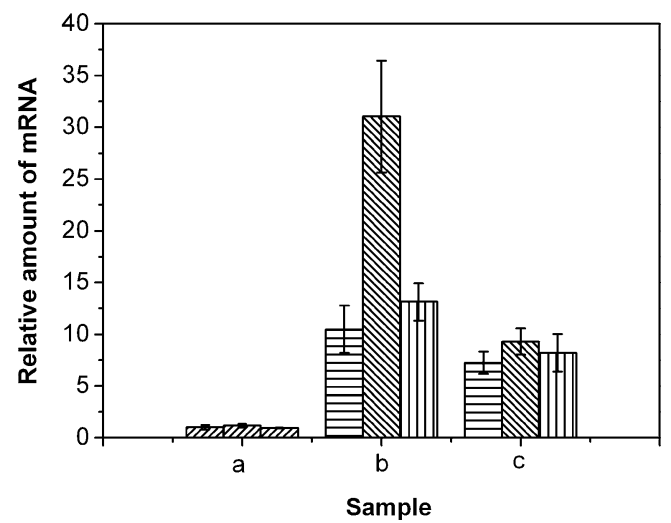

Fig. 4 Relative amounts of mRNA. qRT-PCR was used to quantitate the mRNA levels of the rpoS housekeeping gene and the luc gene expressed in the presence and absence of the 2-chlorotoluene inducer $\left.(250 \mu \mathrm{mol} \mathrm{L})^{-1}\right)$. The transcription levels of rpoS under the induced condition and the $l u c$ gene with or without induction were calculated relative to that of rpoS without induction. The columns in $a$ indicate the relative quantification value of mRNA from the rpoS gene. The value was approximately unity, which confirmed that transcription of rpoS is unaffected by growth condition. The columns in $b$ and $c$ filled with transverse lines, oblique lines, and vertical lines represent the relative amounts of $l u c$ mRNA from BTEX-W, BTEX-SD, and BTEX-SE with and without induction, respectively 
ciency can stabilize an mRNA, the A/U-rich translational enhancer did not stabilize mRNA in our study. Thus, there may be competition between RNase $\mathrm{E}$ and the ribosomes. The internal portions of mRNA bound by ribosomes will be protected from RNase E-mediated endonuclease cleavage. However, other parts of the mRNA, e.g., the $5^{\prime}$ UTR and the translation initiation site, are not protected by ribosomes and can be cleaved readily by RNase E. Thus, the A/U-rich element in our study probably acted as both a translational enhancer and an RNase E target.

Our results also show that different RBS motifs can affect the sensitivity and the signal intensity of a whole-cell biosensor or affect a strategy based on the translational level of a whole-cell biosensor. Other factors, for example the spacing between the SD sequence and the initiation codon, different initiation codons, mRNA stability, and translational termination, can affect the expression efficiency of the corresponding gene [20,36-38]. All of these motifs may also affect the responses of whole-cell biosensors. Combined with these effective methods, improved whole cell biosensors with better sensitivity might be suitable for evaluating the environmental risks of the pollutants in situ.

\section{Conclusions}

The results presented here indicate that engineered 5' UTRs of a reporter gene have dramatic effects on both the signal intensity and the sensitivity of whole-cell biosensors; thus, modification at the transcriptional level and systematic modification at the translational level are effective in improving the response characteristics of a whole-cell biosensor. Although E. coli was used as the host cell in this study, similar SD-like RBS and A/AU-rich enhancer motifs have been found to act as translational enhancing elements in many other bacteria [15, 39-41]. Therefore, the strategy reported here may be applicable to other bacterialbased biosensors.

Acknowledgments This work was supported by the Knowledge Innovation Program of the Chinese Academy of Sciences (KSCX2YW-JS401 and KSCX2-YW-G-072), the National Natural Science Foundation of China (no. 20777089), and the National HighTechnology Research and Development Program ("863" Program) of China (2007AA06A407).

\section{References}

1. Willardson BM, Wilkins JF, Rand TA, Schupp JM, Hill KK, Keim P, Jackson PJ (1998) Development and testing of a bacterial biosensor for toluene-based environmental contaminants. Appl Environ Microbiol 64(3):1006-1012
2. D'Souza SF (2001) Microbial biosensors. Biosens Bioelectron 16 (6):337-353

3. Leveau JH, Lindow SE (2001) Appetite of an epiphyte: quantitative monitoring of bacterial sugar consumption in the phyllosphere. PNAS USA 98(6):3446-3453

4. Miller WG, Brandl MT, Quinones B, Lindow SE (2001) Biological sensor for sucrose availability: relative sensitivities of various reporter genes. Appl Environ Microbiol 67(3):1308-1317

5. Choi YJ, Bourque D, Morel L, Groleau D, Miguez CB (2006) Multicopy Integration and Expression of Heterologous Genes in Methylobacterium extorquens ATCC 55366. Appl Environ Microbiol 72(1):753-759

6. Meer JRVD, Tropel D, Jaspers M (2004) Illuminating the detection chain of bacterial bioreporters. Environ Microbiol 6 (10): $1005-1020$

7. Kim MN, Park HH, Lim WK, Shin HJ (2005) Construction and comparison of Escherichia coli whole-cell biosensors capable of detecting aromatic compounds. J Microbiol Meth 60(2):235-245

8. Stockley PG, Baron AJ, Wild CM, Parsons ID, Miller CM, Holtham CAM, Baumberg S (1998) Dissecting the molecular details of prokaryotic transcriptional control by surface plasmon resonance: the methionine and arginine repressor proteins. Biosens Bioelectron 13(6):637-650

9. Jin V, Singer G, Agosto-Perez F, Liyanarachchi S, Davuluri R (2006) Genome-wide analysis of core promoter elements from conserved human and mouse orthologous pairs. BMC Bioinforma $7(1): 114$

10. Patterson GHAL, Jennifer S (2002) A Photoactivatable GFP for selective photolabeling of proteins and cells. Science 297 (5588):1873-1877

11. Stocker J, Balluch D, Gsell M, Harms H, Feliciano J, Daunert S, Malik KA, van der Meer JR (2003) Development of a set of simple bacterial biosensors for quantitative and rapid measurements of arsenite and arsenate in potable water. Environ Sci Technol 37 (20):4743-4750

12. Bernstein JR, Bulter T, Shen CR, Liao JC (2007) Directed evolution of ribosomal protein $\mathrm{S} 1$ for enhanced translational efficiency of high GC Rhodopseudomonas palustris DNA in Escherichia coli. J Biol Chem 282(26):18929-18936

13. Komarova AV, Tchufistova LS, Dreyfus M, Boni IV (2005) AU-Rich Sequences within 5' Untranslated Leaders Enhance Translation and Stabilize mRNA in Escherichia coli. J Bacteriol 187(4):1344-1349

14. Chang B, Halgamuge S, Tang SL (2006) Analysis of SD sequences in completed microbial genomes: non-SD-led genes are as common as SD-led genes. Gene 373:90-99

15. Komarova AV, Tchufistova LS, Supina EV, Boni IV (2002) Protein S1 counteracts the inhibitory effect of the extended Shine-Dalgarno sequence on translation. RNA 8(9):1137-1147

16. Boni IV, Lsaeva DM, Musychenko ML, Tzareva NV (1991) Ribosome-messenger recognition: mRNA target sites for ribosomal protein S1. Nucl Acids Res 19(1):155-162

17. Subramanian AR (1983) Structure and functions of ribosomal protein S1. Prog Nucleic Acid Res Mol Biol 28:101-142

18. Vimberg V, Tats A, Remm M, Tenson T (2007) Translation initiation region sequence preferences in Escherichia coli. BMC Mol Biol 8:100

19. Lee K, Holland-Staley CA, Cunningham PR (1996) Genetic analysis of the Shine-Dalgarno interaction: selection of alternative functional mRNA-rRNA combinations. RNA 2(12):1270-1285

20. Makrides S (1996) Strategies for achieving high-level expression of genes in Escherichia coli. Microbiol Rev 60(3):512-538

21. Boni I (2006) Diverse molecular mechanisms of translation initiation in prokaryotes. Mol Biol 40(4):587-596

22. Olins P, Rangwala S (1989) A novel sequence element derived from bacteriophage T7 mRNA acts as an enhancer of translation 
of the lacZ gene in Escherichia coli. J Biol Chem 264(29):1697316976

23. Ikeno S, Ogino C, Ito T, Shimizu N (2003) Detection of benzene derivatives by recombinant $E$. coli with Ps promoter and GFP as a reporter protein. Biochem Eng J 15(3):193-197

24. Jandu N, Ho NKL, Donato KA, Karmali MA, Mascarenhas M, Duffy SP, Tailor C, Sherman PM (2009) Enterohemorrhagic Escherichia coli O157:H7 Gene Expression Profiling in Response to Growth in the Presence of Host Epithelia. PLoS ONE 4(3): e4889

25. Vial J, Jardy A (1999) Experimental Comparison of the Different Approaches To Estimate LOD and LOQ of an HPLC Method. Anal Chem 71(14):2672-2677

26. Schmittgen KJLATD (2001) Analysis of Relative Gene Expression Data Using Real-Time Quantitative PCR and the 2- $\Delta \Delta$ CT Method. Methods 25:402-408

27. Tzareva NV, Makhno VI, Boni IV (1994) Ribosome-messenger recognition in the absence of the Shine-Dalgarno interactions. FEBS Lett 337(2):189-194

28. Taghbalout A, Rothfield L (2007) RNaseE and the other constituents of the RNA degradosome are components of the bacterial cytoskeleton. PNAS USA 104(5):1667-1672

29. Coburn GA, Mackie GA (1999) Degradation of mRNA in Escherichia coli: an old problem with some new twists. Prog Nucleic Acid Res Mol Biol 62:55-108

30. Steege DA (2000) Emerging features of mRNA decay in bacteria. RNA 6(8):1079-1090

31. Rabinowitz MWRAJC (1989) The effect of Escherichia coli ribosomal protein $\mathrm{S} 1$ on the translational specificity of bacterial ribosomes. J Biol Chem 264:2228-2235

32. Baker KE, Mackie GA (2003) Ectopic RNase E sites promote bypass of 5'-end-dependent mRNA decay in Escherichia coli. Mol Microbiol 47(1):75-88
33. Kaberdin VR (2003) Probing the substrate specificity of Escherichia coli RNase E using a novel oligonucleotide-based assay. Nucl Acids Res 31(16):4710-4716

34. Li Z, Pandit S, Deutscher MP (1999) RNase G (CafA protein) and RNase $\mathrm{E}$ are both required for the $5^{\prime}$ maturation of $16 \mathrm{~S}$ ribosomal RNA. EMBO J 18(10):2878-2885

35. Chen C, Xu N, Shyu A (1995) mRNA decay mediated by two distinct AU-rich elements from c-fos and granulocyte-macrophage colony-stimulating factor transcripts: different deadenylation kinetics and uncoupling from translation. Mol Cell Biol 15 (10):5777-5788

36. Chen H, Bjerknes M, Kumar R, Jay E (1994) Determination of the optimal aligned spacing between the Shine-Dalgarno sequence and the translation initiation codon of Escherichia coli mRNAs. Nucl Acids Res 22(23):4953-4957

37. Vellanoweth RL, Rabinowitz JC (1992) The influence of ribosome-binding-site elements on translational efficiency in Bacillus subtilis and Escherichia coli in vivo. Mol Microbiol 6 (9):1105-1114

38. Barrick D, Villanueba K, Childs J, Kalil R, Schneider TD, Lawrence CE, Gold L, Stormo GD (1994) Quantitative analysis of ribosome binding sites in E coli. Nucl Acids Res 22(7):1287-1295

39. Zhou W, Edelman GM, Mauro VP (2001) Transcript leader regions of two Saccharomyces cerevisiae mRNAs contain internal ribosome entry sites that function in living cells. PNAS USA 98 (4):1531-1536

40. Brumlik MJ, Storey DG (1998) Post-transcriptional control of Pseudomonas aeruginosa lasB expression involves the $5^{\prime}$ untranslated region of the mRNA. FEMS Microbiol Lett 159(2):233-239

41. Bycroft M, Hubbard TJP, Proctor M, Freund SMV, Murzin AG (1997) The Solution Structure of the S1 RNA Binding Domain: A Member of an Ancient Nucleic Acid-Binding Fold. Cell 88 (2):235-242 